\title{
The essentiality of selenium for humans, animals, and plants, and the role of selenium in plant metabolism and physiology
}

\author{
F. Garousi \\ e-mail: farzaneh@agr.unideb.hu \\ University of Debrecen, Faculty of Agricultural and \\ Food Sciences and Environmental Management, \\ Institute of Food Technology, \\ HU-4032 Debrecen, Böszörményi út 138., Hungary
}

\begin{abstract}
After its discovery, selenium was most noted for its harmful effects. Selenium was the first element identified to occur in native vegetation at levels toxic to animals. Poisoning of animals can occur through consumption of plants containing toxic levels of selenium. Livestock consuming excessive amounts of selenized forages are afflicted with "alkali disease" and "blind staggers". Typical symptoms of these diseases include loss of hair, deformed hooves, blindness, colic, diarrhoea, lethargy, increased heart and respiration rates, and eventually death. On the other hand, selenium deficiency in animal feeds can cause "white muscle disease", a degenerative disease of the cardiac and skeletal muscles. In this regard, this review paper attempts to summarize the essentiality of selenium for humans, animals, and plants and the role of selenium in plant metabolism and physiology.
\end{abstract}

Keywords and phrases: selenium deficiency, essentiality of selenium, selenium in plant metabolism and physiology 


\section{Essentiality of selenium for humans, animals, and plants}

Perceptions of selenium changed when Schwarz \& Foltz in 1957 reported that additions of selenium prevented liver necrosis in rats (Rattuss pp.) deficient in vitamin E. Its role in human health was established in 1973, when selenium, the last of 40 nutrients proven to be essential, was shown to be a component of glutathione peroxidase (GSHx), an enzyme that protects against oxidative cell damage. The United States' recommended daily allowance for selenium is 50 to $70 \mu \mathrm{g}$ in human diets. Currently, all of the known functions of selenium as an essential nutrient in humans and other animals have been associated with selenoproteins (Kopsell \& Kopsell, 2007).

The essentiality of Se for higher plants is still under debate, but Se is considered a beneficial nutrient for many plant species (Pilon-Smits et al., 2009) - maybe for better oxidative stress resistance (Hartikainen, 2005). Plants readily take up and assimilate Se, a capacity that may be used to diminish both Se deficiency and toxicity in animals and humans. Plants can be used to clean up surplus Se from polluted areas (phytoremediation), and Se-enriched plant material may be considered fortified food (biofortification) (El Mehdawi et al., 2012; El-Ramady et al., 2014b). It is well known that the element Se is considered a limited and not renewable resource on earth. It is a necessary element in humans, animals, microorganisms, and some other eukaryotes; but as yet its necessity to plants is in dispute. However, Se has not been approved to be an essential microelement to artery plants. There are some documents that Se may be essential for growth and development in algae (Pilon-Smits et al., 2009). Also without any doubt, adequate amounts of Se are significant to animal and human health, and some Se compounds have been found to be active against cancers. A limited number of plants growing on Se-enriched soils can accumulate very high amounts of Se (i.e. hyperaccumulate Se) and are classified as Se tolerant; however, many more plants do not accumulate Se to any excess extent and are Se sensitive. Plants vary considerably in their physiological and biochemical reply to Se, and a revision of the physiological reply of plants to Se is presented; especially growth, uptake, transport, and interplay of Se with other minerals, as pointed out by de Filippis (2010).

Even in the best-studied Se-accumulating plant, Astragalus pectinatus, the results of additional Se application in experiments have had differing results (Stadtman, 1990). It is fair to point out that other nutrients can complex the situation, such as sulphates, phosphates; however, the experiments so far have not used controls where residual Se is not present at all; and indeed such 
experiments may be nearly impossible to perform (Stadtman, 1996).

This is simply because there will always be trace amounts of Se in plants, coming from impurities in the nutrients used or even coming from the atmosphere. A substitute approach trying to resolve essentiality was an attempt at specifying Se interpolation into Se-dependent enzymes, with an integral SeCys residue as present in animals and bacteria (Axley et al., 1991). As Filippis (2010) contends, the available evidence from molecular studies so far is quite strong that there is no clear evidence for necessary selenoproteins in higher plants, but part of the machinery for the synthesis of selenoproteins may be present in plants.

It is well known that Se is a contradictory nutrient since it is called the essential poison - too much of it in the diet can be toxic, while too little can result in chronic and sometimes fatal deficiency (Reilly, 2006). Organisms that require Se for normal cellular function contain necessary selenoproteins, such as glutathione peroxidase, formate dehydrogenase, and selenophosphate synthase. Interestingly, the interpolation of selenocysteine into these selenoproteins is directed by a specific tRNA that recognizes a UGA-opal codon (Ellis and Salt, 2003). The UGA codon normally acts to terminate translation. In combination with a selenocysteine insertion sequence (SECIS), the UGA codon is identified by the selenocysteine tRNA, which manages the insertion of selenocysteine (Low and Berry, 1996). There is not any strict evidence for the specific incorporation of selenocysteine in vascular plants. Various selenoproteins that involve a glutathione peroxidase homologue and selenocysteine tRNA have been specified in the plant system of Chlamydomonas reinhardtii (Fu et al., 2002). And as suggested by Ellis \& Salt (2003), evidence for the specific insertion of selenocysteine in vascular plants is less certain. Therefore, it could be concluded that the necessity of Se for higher plants is still uncertain, but Se is marked as a beneficial nutrient for many plant species.

\subsection{Is selenium physiologically important for higher plants?}

Se has not been known as an essential element for higher plants as yet, although its role has been regarded to be beneficial for plants that are capable of a large-scale accumulation of this element (Shanker, 2006). According to Hamilton (2004), the role of Se in plants mainly depends on its concentration. Se has three levels of biological activity: trace concentrations are essential for normal growth and development, moderate concentrations can be stored to maintain homeostatic functions, and elevated concentrations can eventuate in toxic effects, as Fig. 1 shows. 


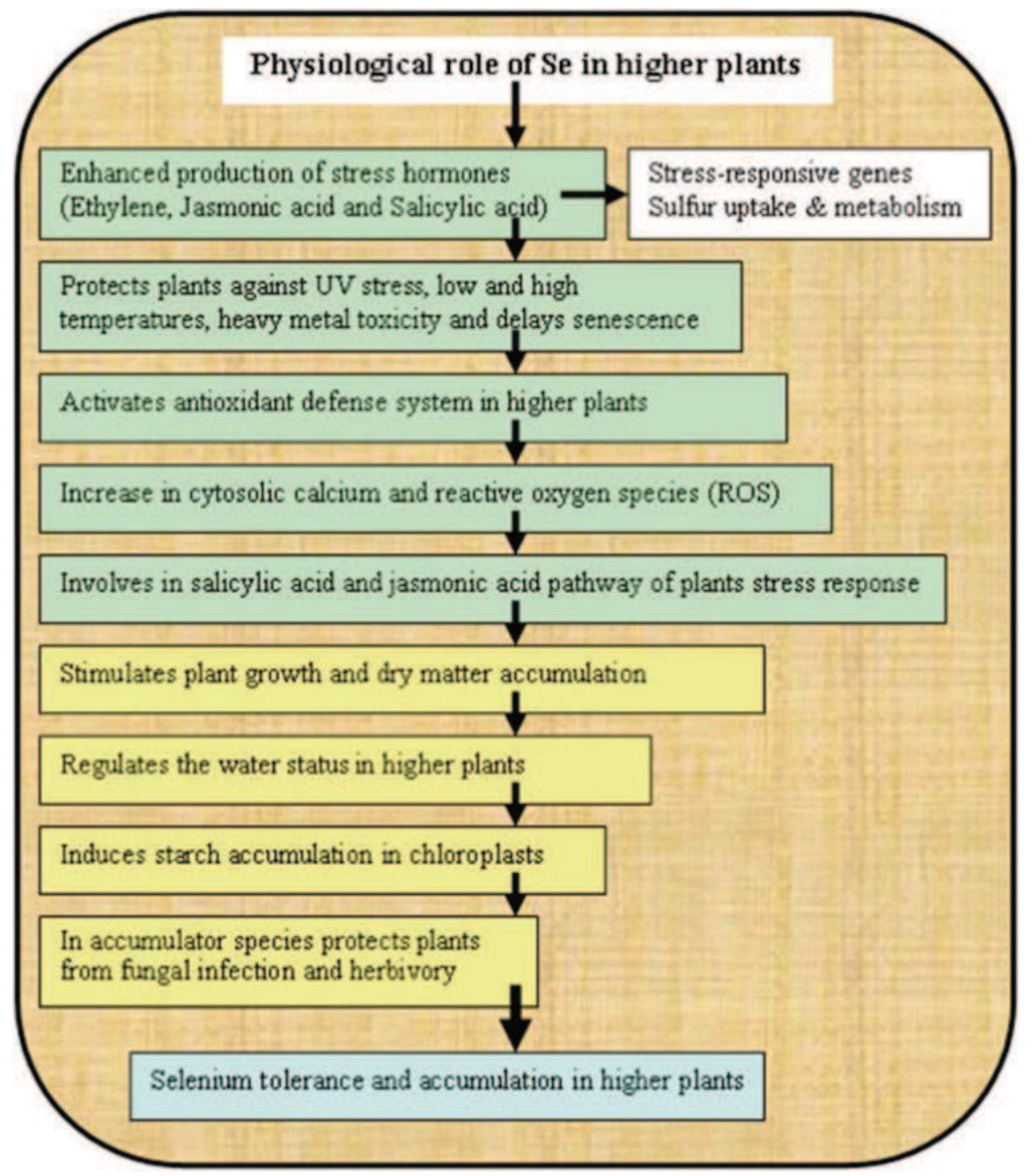

Figure 1: Physiological functions or roles of Se in higher plants (Hasanuzzaman et al., 2010; Hajiboland, 2012; El-Ramady et al., 2014)

Combs \& Combs (1986), Germ \& Stibilj (2007), and Pilon-Smits (2015) investigated in many studies the function of Se in plants, and they found that there is little evidence for the essentiality of Se for all plants. Hartikainen (2005) did several studies on some grasses and vegetables and indicated that with a proper Se addition the growth rate of these plants may be increased. Certain data indicated that this element may be required for 
Se-accumulating plants (Moxon and Olson, 1974). Some Se compounds with cysteine and methionine were found in such plants such as Astragalus species, but their metabolic functions have not been definitely established. Whereas Se-accumulator plants synthesise Se-methyl-cysteine, non-accumulator species produce Se-methyl-methionine. Kabata-Pendias (2011) pointed out that the physiological significance of this difference has not been not identified yet.

Several selenoamino acids, selenomethionine (SeMet), selenocysteine (SeCys), and Se-methylselenocysteine (SeMSC) in association with glutathione peroxidases were found in both bacteria and higher plants (Kabata-Pendias, 2011). Selenocysteine, methylselenocysteine, selenomethionine, selenotaurine, selenobetaine, selenoecholine, dimethylselenine, dimethyldiselenide, and trimethylselenium are different Se species in plants (Pyrzynska, 1995). For example, SeMet is a predominant form of Se in cereal grains, legume seeds, and lentils (up to $95 \%$ of total Se), while SeMSC in vegetables (Djujic et al., 2001).

Singh et al. (1980) were the first ones to write about the positive effect of Se on plant growth. They showed the application of $0.5 \mathrm{mg} \mathrm{kg}^{-1} \mathrm{Se}$, as selenite stimulated the growth and dry matter yield of Indian mustard (Brassica juncea L.). They also found that Se applied in low concentrations can increase the growth and antioxidative volume of both mono- and dicotyledonous plants. Hartikainen et al. (1997) demonstrated a positive response of lettuce (Lactucasativa L.) growth to Se, while Djanaguiraman et al. (2005) obtained the same results in relation to soybean (Glycine max L.).

At a higher supplementation level than $29 \mathrm{mg} \mathrm{kg}^{-1}$ soil, Se inhibited the growth and germination of tomato, lettuce, and radish (Raphanus sativus L.) seeds (Carvalho et al., 2003). Hence, Se has an effect on germination. But according to Hasanuzzaman et al. (2010) the positive effect on germination was linked to antioxidative activity, and selenite improved germination of bitter gourd (Momordica charantia L.) seeds at sub-optimal temperatures (Chen and Sung, 2001).

Se could be used for the phytoremediation in Se-contaminated fields. Plants that have a high capacity to accumulate and tolerate Se are suitable for it (Terry et al., 2000). But, generally, most plants have a low tolerance to high Se amounts, and they contain less than $25 \mu \mathrm{g}$ Se $\mathrm{g}^{-1}$ dry weight (DW), being considered as non-accumulators (White et al., 2004). Non-accumulators are susceptible to high Se concentration, but tolerance and accumulation of Se, even at high concentrations, is possible for them without reduction in growth (Rani et al., 2005).

The critical Se concentration in plant tissues, which decreased the yield in Indian mustard, was $105 \mu \mathrm{g} \mathrm{g}^{-1} \mathrm{DW}$, in maize (Zea mays L.) $77 \mu \mathrm{g} \mathrm{g}^{-1} \mathrm{DW}$, 
in rice (Oryza sativa L.) $42 \mu \mathrm{g} \mathrm{g}^{-1} \mathrm{DW}$, and in wheat $19 \mu \mathrm{g} \mathrm{g}^{-1} \mathrm{DW}$, when Se additions, such as selenite, were 5, 5, 4, and $10 \mu \mathrm{g} \mathrm{g}^{-1}$ soil for Indian mustard, maize, wheat, and rice respectively (Rani et al., 2005). Depending on the plant species, growth stage, and plant organs, Se uptake and metabolism will be different. Broccoli (Brassica oleracea var. italica) is known for its ability to accumulate high levels of Se, with a greater number of the selenoamino acids in the form of Se-Met (SeMeSeCys) (Lyi et al., 2005). Most plants accumulate more Se in shoot and leaf than in root tissues, but there are exceptions (Zayed et al., 1998). Se concentrations in the higher leaves, roots, stolons, and tubers of potato increased with increasing Se supplementation (Turakainen, 2007). The highest Se concentration was observed in young upper leaves, roots, and stolons, and indicated that added selenate was efficiently utilized and taken up at an early stage. The Se concentration declined in the upper parts, roots, and stolons of potato plants during the growing period, whereas an intensive accumulation happened in immature and mature tubers (Turakainen, 2007).

Se accumulation was also affected by the methods of application, where foliar application with selenate significantly increased Se content in tea leaves (Hu et al., 2003). According to other results, the Se content of pea seeds obtained from untreated and once or twice foliar-treated plants was directly proportionate to the number of sprayings (Smrkolj et al., 2006). Several studies proved that Se is taken up from the soil by plants primarily as selenate $\left(\mathrm{SeO}_{4}^{2-}\right)$ or selenite $\left(\mathrm{SeO}_{3}^{2-}\right)$ (Ellis and Salt, 2003). Due to the faster incorporation of selenite than selenate, a higher toxicity of selenite compared to selenate has been suggested (Lyons et al., 2005). The uptake of selenate into roots and its dispersion in plants is much faster than that of selenite (Cartes et al., 2005). The total Se accumulation in a plant was about tenfold higher from selenate compared to selenite, as De Souza et al. (1998) reported.

What we can conclude from all outcomes is as follows: Se as an essential element for higher plants has not yet been classified, but it has an important beneficial role for plants that can accumulate large amounts of this element. Although the essentiality of selenoproteins in higher plants has not been proved, syntheses of selenoproteins in some plants, e.g. sugar beet, were reported. Se, at low concentrations, increases the growth and antioxidative capacity of both mono- and dicotyledonous plants. The physiological importance of Se for higher plants could be evaluated within the following topics: anti-oxidative and pro-oxidative effects of Se and the role of Se under abiotic stresses. 


\subsubsection{The role of selenium in plant metabolism and physiology}

Environmental selenite, which is prevalent in reducing environments, and selenite, which is prevalent in toxic environments, are taken up non-specifically by plants typically using transporters for sulphur (S) analogues. Via the sulphate assimilation pathway into selenocysteine (SeCys), selenomethionine (SeMet), and other organic S compounds, these inorganic forms of Se may be assimilated. This process can happen in the shoot, but it is thought to take place in the root. When seleno-amino acids get incorporated into proteins, replacing Cys and Met, this accidentally impairs protein function and thus results in toxicity (Stadtman, 1990). Most plants can metabolize SeMet into volatile dimethylselenide (DMSe), which may help avoid toxicity (Terry et al., 2000). Another potential Se detoxification mechanism in plants is the breakdown of SeCys into elemental Se and alanine (Van Hoewyk et al., 2005; Prokisch et al., 2008). Both volatilization and separation of SeCys are nonspecific, using enzymes that function in S metabolism. Fig. 2 summarizes Se metabolism in plants (Terry et al., 2000; Van Hoewyk et al., 2007; Pilon-Smits, 2015).

Not only these general mechanisms take place in plants, which metabolize Se inadvertently, but some plants may also be able to discriminate between Se and S analogues, and so these can be said to have Se-specific metabolism. For instance, these plants can methylate SeCys into methyl-SeCys, which serves as a very effective Se detoxification mechanism since methyl-SeCys does not get combined into proteins (Neuhierl \& Böck, 1996). This methylation process is mediated by the enzyme SeCys methyltransferase (SMT). Plants that contain this enzyme are called Se hyperaccumulator and can fill up to $1.5 \%$ of their dry weight as Se $\left(15,000 \mathrm{mg} \mathrm{kg}^{-1} \mathrm{DW}\right.$, Beath et al., 1939a, b). However, SMT was also detected in broccoli (Brassica oleracea) (Lyi et al., 2005), and methyl-SeCys was found in several Allium species such as garlic (Ge et al., 1996). Although these species are known to be sulphur-loving, they are not hyperaccumulators, but due to high levels of sulphate that they accumulate the amount of their Se uptake is remarkable. Hence, sometimes they are known as Se-accumulator plants.

Hyperaccumulators of Se have several properties that separate them from other species. True Se hyperaccumulation occurs in $4-5$ genera in the Brassicaceae, Fabaceae, and Asteraceae. They occur predominantly or even exclusively on seleniferous soils (Beath et al. 1939a, b). They accumulate $\sim 100$-fold higher Se levels and have higher tissue Se/S levels than the surrounding vegetation (Lauchli, 1993). Hyperaccumulators accumulate organic forms such as 
methyl-SeCys and selenocystathionine, whereas most plants accumulate inorganic Se (Anderson, 1993).

DMSe

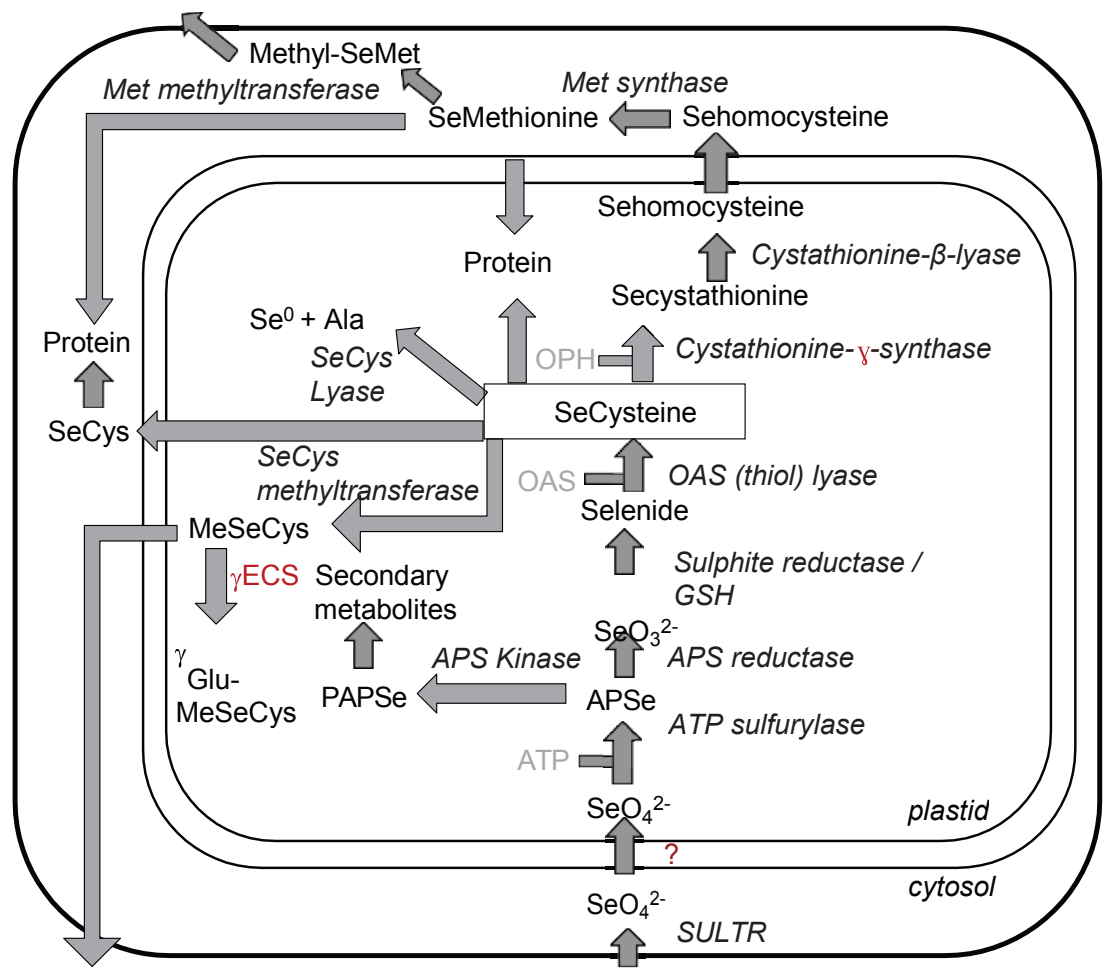

$\mathrm{DMDSeSeO}_{4}{ }^{2}$

Figure 2: Proposed model for Se assimilation in plants

Enzymes are shown in italic and metabolites in black or grey. SULTR - sulphate/selenate transporter, APSe adenosine phosphoselenate, PAPSe phospho adenosine phosphoselenate, OAS O-acetylserine, OPH O-phosphohomoserine, SeCys selenocysteine, (Se)Met (seleno) methionine, Ala alanine, MeSeCysmethyl-SeCys, gGlu-MeSeCysg-glutamyl MeSeCys, gECSgglutamylcysteine synthetase, GSH glutathione, DMSe dimethyl-selenide, DMDSe dimethyldiselenide

Hyperaccumulators are completely tolerant to their extreme Se levels and often even grow better under high Se conditions than without Se because organic forms of Se do not interfere with S metabolism (Broyer et al., 1972; El 
Mehdawi et al., 2012). Hyperaccumulators can volatilize Se, but mostly in the form of dimethyldiselenide (DMDSe), which originates from methyl-SeCys, as in the case of other plants (Terry et al., 2000). Selenium hyperaccumulators also show tissue-specific and organ-specific sequestration patterns that are different from other plants.

Depending on non-accumulators, a larger fraction of the Se in hyperaccumulators is relocated from the root to shoot; also, a larger fraction is remobilized from older leaves to young leaves and reproductive organs, particularly pollen and ovules (Quinn et al., 2011a, b). Through leaves, hyperaccumulators store most of their Se in the vacuoles of epidermal cells, which may include the trichomes (leaf hairs) (Freeman et al., 2006, 2010). For comparison, non-hyperaccumulator Arabidopsis thaliana and Brassica juncea were found to store most of their Se in the form of selenate in the vascular bundles and to contain higher Se levels in leaves than in floral tissues (van Hoewyk et al., 2005; Freeman et al., 2006; Quinn et al., 2011a). Interestingly, selenate uptake in Se hyperaccumulators is not inhibited by sulphate, suggesting that they have a selenate-specific transporter; this is in sharp contrast to the nonhyperaccumulator $B$. juncea and may explain the elevated $\mathrm{Se} / \mathrm{S}$ ratios that are typical for hyperaccumulators (White et al., 2007). In like manner, Se and $S$ remobilization in hyperaccumulators follows diverse patterns both developmentally and seasonally (Galeas et al., 2007; Quinn et al., 2011a). Selenium levels are highest in young leaves and reproductive tissues, while $\mathrm{S}$ levels are highest in mature leaves. Leaf Se levels in the field peak in early spring, while leaf $\mathrm{S}$ levels sharpen in midsummer. In non-hyperaccumulators, both Se and S amounts peaked in midsummer (Galeas et al., 2007; Pilon-Smits, 2015).

\subsubsection{Accumulator to non-accumulator plants}

Rosenfeld and Beath (1964) and Shrift (1973) divided plants into three groups on the basis of their ability to accumulate Se when grown on high Se soils. The first two groups of plants are referred to as Se hyperaccumulatoror indicator plants. These grow well on soil containing high levels of available Se, and some have been used to locate seleniferous soils. Plants in Group 1 are called primary indicators and include many species of Astragalus, Machaeranthera, Haplopappus, and Stanleya. These species absorb high concentrations of Se, which might mean hundreds or, occasionally, even thousands of milligrams dry weight per kilogram. Plants in Group 2 are referred to as secondary Se $a b$ sorbers. They belong to a number of genera including Aster, certain species of Astragalus, Atriplex, Castilleja, Grindelia, and Gutierrezia and certain species 
of Machaeranthera and Mentzelia. They rarely concentrate more than 50 to

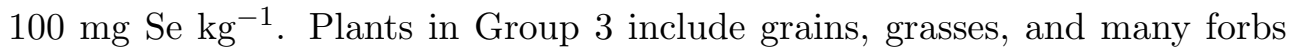
that do not usually accumulate Se in excess of $50 \mathrm{mg} \mathrm{Se} \mathrm{kg}^{-1}$ when grown on seleniferous soil.

Some plants growing on seleniferous soils accumulate surprisingly low levels of Se. White clover (Trifolium repens L.), buffalo grass (Buchloe dactyloides [Nutt.] Engelm.), and grama (Bouteloua sp.) are poor accumulators of Se. On the other hand, high sulphur-containing plants, such as the Brassica sp. (mustard, cabbage, broccoli, and cauliflower) and other Cruciferae, are relatively good concentrators of Se $(N A S-N R C, 1983)$. Absorption of Se and S by plants may be correlated with each other (Shrift, 1973).

\section{References}

[1] K. Schwarz, C. M. Foltz, Selenium as an integral part of factor 3 against dietary necrotic liver degeneration. Journal of American Chemistry Society, 70. (1957) 3292-3293.

[2] D. A. Kopsell, D. E. Kopsell, Selenium. Chapter 18. In: A. V. Barker, D. J. Plibeam (eds), Handbook of plant nutrition. CRC Press. (2007) $515-549$.

[3] E. A. H. Pilon-Smits, C. F. Quinn, W. Tapken, M. Malagoli, M. Schiavon, Physiological functions of beneficial elements. Current Opinion in Plant Biology, 12. (2009) 267-274.

[4] H. Hartikainen, Biogeochemistry of selenium and its impact on food chain quality and human health. Journal of Trace Elements in Medicine and Biology, 18. (2005) 309-318.

[5] A. F. El Mehdawi, J. J. Cappa, S. C. Fakra, J. Self, E. A. H. PilonSmits, Interactions of selenium hyperaccumulators and nonaccumulators during cocultivation on seleniferous or nonseleniferous soil - the importance of having good neighbors. New Phytologist, 194. (2012) 264277.

[6] H. El-Ramady, T. Alshaal, É. Domokos-Szabolcsy, T. Shalaby, Y. Bayoumi, N. Elhawat, A. Sztrik, J. Prokisch, M. Fári, Selenium and its role in higher plants. In: E. Lichtfouse (ed.), Environmental chemistry for a sustainable world 6 . Springer, Berlin. (2014b). 
[7] L. F. De Filippis, Biochemical and molecular aspects in phytoremediation of selenium. In: M. Ashraf, M. Ozturk, M. S. A. Ahmad (eds), Plant adaptation and phytoremediation, Springer, Dordrecht/Heidelberg/London/New York. (2010).

[8] T. C. Broyer, C. M. Johnson, R. P. Hudson, Selenium and nutrition of Astragalus I: Effects of selenite or selenate supply on growth and selenium content. Plant and Soil, 36. (1972) 635-649.

[9] T. C. Stadtman, Selenium biochemistry known as Se. Annual Review of Biochemistry, 59. (1990) 111-128.

[10] T. C. Stadtman, Selenocysteine. Annual Review of Biochemistry, 65. (1996) 83-100.

[11] M. J. Axley, A. Boeck, T. C. Stadtman, Catalytic properties of an Escherichia coli format dehydrogenase mutant in which sulphur replaces selenium. Proceedings of the National Academy of Sciences, USA, 88. (1991) 8450-8454.

[12] C. Reilly, Selenium in food and health. $2^{\text {nd }}$ ed. Springer, Berlin. (2006).

[13] D. R. Ellis, D. E. Salt, Plants, selenium and human health. Current Opinion in Plant Biology, 6. (2003) 273-279.

[14] S. C. Low, M. J. Berry, Knowing when not to stop: selenocysteine incorporation in eukaryotes. Trends in Biochemical Sciences, 21. (1996) 203-208.

[15] L. H. Fu, X. F. Wang, Y. Eyal, Y. M. She, L. J. Donald, K. G. Standing, G. Ben-Hayyim, A seleno protein in the plant kingdom. The Journal of Biological Chemistry, 277. (2002) 25983-25991.

[16] A. K. Shanker, Countering UV-B stress in plants: does selenium have a role? Plant and Soil, 282. (2006) 21-26.

[17] S. J. Hamilton, Review of selenium toxicity in the aquatic food chain. Science of the Total Environment, 326. (2004) 1-31.

[18] G. F. Combs, S. B. Combs, The role of selenium in nutrition. Academic Press, Orlando. (1986). 
[19] M. Germ, V. Stibilj, I. Kreft, Metabolic importance of selenium for plants. European Journal of Plant Science and Biotechnology, 1. (2007) 91-97.

[20] E. A. H. Pilon-Smits, Selenium in plants. In: U. Luettge, W. Beyschlag (eds), Progress in botany 76, Springer International Publishing, Cham. (2015) 93-107.

[21] A. L. Moxon, O. E. Olson, Selenium in agriculture. In: Selenium. Van Nostrand, New York, (1974) 675.

[22] E. Kabata-Pendias, Trace elements in soils and plants. $4^{\text {th }}$ ed. CRC Press Taylor \& Francis, Boca Raton. (2011).

[23] M. Hasanuzzaman, M. A. Hossain, F. Masayuki, Selenium in higher plants: physiological role, antioxidant metabolism and abiotic stress tolerance. Journal of Plant Science, 5. (2010) 354-375.

[24] R. Hajiboland, Effect of micronutrient deficiencies on plants, stress responses. In: P. Ahmad, M. N. V. Prasad (eds), Abiotic stress responses in plants: metabolism, productivity and sustainability. Springer, Berlin. (2012) 283-329.

[25] H. El-Ramady, É. Domokos-Szabolcsy, N. Abdalla, T. Alshaal, T. Shalaby, A. Sztrik, J. Prokisch, M. Fári, Selenium and nano-selenium in agroecosystems. Environmental Chemistry Letter, 12. (2014) 495-510.

[26] K. Pyrzynska, Solid phase extraction for preconcentration and separation of selenium. Solvent Extraction Ion Exchange, 13. (1995) 369-389.

[27] I. Djujic, O. Jozanov-Stankov, M. Milovac, O. Bosnic, V. Djermanovic, The impact of consuming wheat naturally enriched with selenium on trace elements and antioxidant defense in humans. $3^{\text {rd }}$ International symposium on trace elements in human, New Perspec, Athens (2001). 281-304.

[28] M. Singh, H. Singh, D. K. Bhandari, Interaction of selenium and sulphur on the growth and chemical composition of raya. Soil Science, 129. (1980) 238-244.

[29] H. Hartikainen, P. Ekholm, V. Piironen, T. Xue, T. Koivu, M. YliHalla, Quality of the ryegrass and lettuce yields as affected by selenium fertilization. Agricultural and Food Science Finl., 6. (1997) 381-387. 
[30] K. M. Carvalho, M. T. Gallardo-Williams, R. F. Benson, D. F. Martin, Effects of selenium supplementation on four agricultural crops. Journal of Agricultural and Food Chemistry, 51.(2003) 704-709.

[31] C. C. Chen, J. M. Sung, Priming bitter gourd seeds with selenium solution enhances germinability and antioxidative responses under suboptimal temperature. Physiologia Plantarum, 111. (2001) 9-16.

[32] N. Terry, A. M. Zayed, M. P. de Souza, A. S. Tarun, Selenium in higher plants. Annual Review of Plant Physiology and Plant Molecular Biology, 51. (2000) 401-432.

[33] P. J. White, H. C. Bowen, P. Parmaguru, M. Fritz, W. P. Spracklen, R. E. Spiby, M. C. Meacham, A. Mead, M. Harriman, L. J. Trueman, B. M. Smith, B. Thomas, M. R. Broadley, Interactions between selenium and sulphur nutrition in Arabidopsis thaliana. Journal of Experimental Botany, 55. (2004) 1927-1937.

[34] N. Rani, K. S. Dhillo, S. K. Dhillon, Critical levels of selenium in different crops grown in an alkaline silty loam soil treated with seleniteSe. Plant and Soil, 277. (2005) 367-374.

[35] S. M. Lyi, L. I. Heller, M. Rutzke, R. M. Welch, L. V. Kochian, L. Li, Molecular and biochemical characterization of the selenocysteine Semethyltranferase gene and Se-methylselenocysteine synthesis in broccoli. Plant Physiology, 138. (2005) 409-420.

[36] A. M. Zayed, C. M. Lytle, N. Terry, Accumulation and volatilization of different chemical species of selenium by plants. Planta, 206. (1998) $284-289$.

[37] M. Turakainen, Selenium and its effects on growth, yield and tuber quality in potato. University of Helsinki, Helsinki. (2007).

[38] Q. X. Hu, J. U. G. Pang, Effect of selenium on the yield and quality of green tea leaves harvested in early spring, (2003).

http://www.aseanfood.info/Articles/11019553.pdf.

[39] P. Smrkolj, M. Germ, I. Kreft, V. Stibilj, Respiratory potential and Se compounds in pea (Pisumsativum L.) plants grown from Se-enriched seeds. Journal of Experimental Botany, 57. (2006) 3595-3600. 
[40] G. H. Lyons, J. C. R. Stangoulis, R. D. Graham, Tolerance of wheat (Triticum aestivum L.) to high soil and solution selenium levels. Plant and Soil, 270. (2005) 179-188.

[41] P. Cartes, L. Gianfera, M. L. Mora, Uptake of selenium and its antioxidative activity in ryegrass when applied a selenate and selenite forms. Plant and Soil, 276. (2005) 359-367.

[42] M. P. de Souza, D. Chu, M. Zhao, A. M. Zayed, S. E. Ruzin, D. Schichnes, N. Terry, Rhizosphere bacteria enhance selenium accumulation and volatilization by Indian mustard. Plant Physiology, 119. (1998) $565-574$.

[43] D. Van Hoewyk, S. E. Abdel-Ghany, C. Cohu, S. Herbert, P. Kugrens, M. Pilon, E. A. H. Pilon-Smits, The Arabidopsis cysteine desulfurase CpNifS is essential for maturation of iron-sulphur cluster proteins, photosynthesis, and chloroplast development. Proceedings of the National Academy of Sciences, USA, 104. (2007) 5686-5691.

[44] B. Neuhierl, A. Böck, On the mechanism of selenium tolerance in selenium accumulating plants. Purification and characterization of a specific selenocysteine methyltransferase from cultured cells of Astragalusbisulcatus. European Journal of Biochemistry, 239. (1996) 235-238.

[45] O. A. Beath, C. S. Gilbert, H. F. Eppson, The use of indicator plants in locating seleniferous areas in the Western United States. I. General. American Journal of Botany, 26. (1939a) 257-269.

[46] O. A. Beath, C. S. Gilbert, H. F. Eppson, The use of indicator plants in locating seleniferous areas in the Western United States. II. Correlation studies by states. American Journal of Botany, 26. (1939b) 296-315.

[47] H. H. Ge, X. J. Cai, J. F. Tyson, P. C. Uden, E. R. Denover, E. Block, Identification of selenium species in selenium-enriched garlic, onion and broccoli using high-performance ion chromatography with inductively coupled plasma mass spectrometry detection. Analytical Communications, 33. (1996) 279-281.

[48] A. Lauchli, Selenium in plants: uptake, functions, and environmental toxicity. Botanica Acta, 106. (1993) 455-468. 
[49] J. W. Anderson, Selenium interactions in sulphur metabolism. In: L. J. De Kok (ed.), Sulphur nutrition and assimilation in higher plants regulatory, agricultural and environmental aspects. SPB Academic, The Netherlands. (1993) 49-60.

[50] C. F. Quinn, C. N. Prins, J. L. Freeman, A. M. Gross, L. J. Hantzis, R. J. B. Reynolds, S. Yang, P. A. Covey, G. S. Bañuelos, I. J. Pickering, E. A. H. Pilon-Smits, Selenium accumulation in flowers and its effects on pollination. New Phytologist, 192. (2011a) 727-737.

[51] C. F. Quinn, K. Wyant, A. L. Wangeline, J. Shulman, M. L. Galeas, J. R. Valdez, M. W. Paschke, E. A. H. Pilon-Smits, Enhanced decomposition of selenium hyperaccumulator litter in a seleniferous habitat evidence for specialist decomposers. Plant and Soil, 341. (2011b) 51-61.

[52] J. L. Freeman, L. H. Zhang, M. A. Marcus, S. Fakra, S. P. McGrath, E. A. H. Pilon-Smits, Spatial imaging, speciation and quantification of selenium in the hyperaccumulator plants Astragalusbisulcatus and Stanleyapinnata. Plant Physiology, 142. (2006) 124-134.

[53] J. L. Freeman, M. Tamaoki, C. Stushnoff, C. F. Quinn, J. J. Cappa, J. Devonshire, S. Fakra, M. A. Marcus, S. McGrath, D. Van Hoewyk, E. A. H. Pilon-Smits, Molecular mechanisms of selenium tolerance and hyperaccumulation in Stanleyapinnata. Plant Physiology, 153. (2010) 1630-1652.

[54] D. Van Hoewyk, G. F. Garifullina, A. R. Ackley, S. E. Abdel-Ghany, M. A. Marcus, S. Fakra, K. Ishiyama, E. Inoue, M. Pilon, H. Takahashi, E. A. H. Pilon-Smits, Overexpression of AtCpNifS enhances selenium tolerance and accumulation in Arabidopsis. Plant Physiology, 139. (2005) $1518-1528$.

[55] P. J. White, H. C. Bowen, B. Marshall, M. R. Broadley, Extraordinarily high leaf selenium to sulfur ratios define "Se-accumulator" plants. Annals of Botany, 100. (2007) 111-118.

[56] M. L. Galeas, L. H. Zhang, J. L. Freeman, M. Wegner, E. A. H. PilonSmits, Seasonal fluctuations of selenium and sulphur accumulation in selenium hyperaccumulators and related non-accumulators. New Phytologist, 173. (2007) 517-525. 
[57] I. Rosenfeld, O. A. Beath, Selenium. Geobotany, biochemistry, toxicity and nutrition. Academic Press, New York. (1964).

[58] A. Shrift, Selenium compounds in nature and medicine. Metabolism of selenium by plants and microorganisms. In: D. L. Klayma, W. H. H. Gunther (eds), Organic selenium compounds: their chemistry and biology. Wiley Interscience, New York (1973) 763-814. 